\title{
EFEKTIFITAS BIOLARVASIDA EKSTRAK KULIT BATANG AVICENNIA MARINA TERHADAP JENTIK VEKTOR DEMAM BERDARAH (Aedes aegypti)
}

\author{
Shinta Arum Indah Putri ${ }^{1}$, Ni Wayan Nanik Santika², Indah Nuraini ${ }^{3}$ \\ ${ }^{1}$ Mahasiswa Jurusan Biologi, Fakultas Sains dan Teknologi, Universitas Airlangga \\ ${ }^{2}$ Staff Pengajar, Sekolah Menengah Atas Dr. Soetomo, Surabaya \\ 3Peneliti, Laboratorium Human Genetic, Lembaga Penyakit Tropis, Universitas \\ Airlangga
}

\begin{abstract}
The Effectiveness of Avicennia Marina Bark Extract as Biolarvacide on Aedes aegypti Larvae as the Vector of Dengue Fever. The data from the Ministry of Health of the Republic of Indonesia, related to the number of Dengue fever patients in 2013 , recorded 45.85 per 100,000 populations $(112,511$ cases $)$ with a mortality rate of 871 cases $(0.77 \%)$. The government effort and the use of synthetic mosquito repellents did not give an optimum result. Besides, the synthetic mosquito repellents contained toxic chemical substances for the users. This study aimed to know the toxicity effect of Avicennia marina bark extract on the mortality of Aedes aegypti larvae. This study used a maceration method for producing Avicennia marina bark extract. The toxicity of the collected extract was tested to Aedes aegypti larvae with various concentrations, namely $0 \mathrm{ppm}, 1,000 \mathrm{ppm}, 2,000 \mathrm{ppm}, 3,000 \mathrm{ppm}$, 4,000 ppm, and 5,000 ppm during the 24-hour incubation period. Based on the result of the observation and discussion, it was known that the mortality rate of the mosquito larvae after 24 hours of treatment was 55\% (11 larvae) at the lowest concentration (1,000 ppm), 81\% (18 larvae) at $2000 \mathrm{ppm}, 100 \%$ (20 larvae) at $3,000 \mathrm{ppm}, 100 \%$ (20 larvae) at 4,000 ppm, and 100\% (20 larvae) at 5,000 ppm. The average increase in the mortality rate of Aedes aegypti larvae occurred along with the increase in the concentration of Avicennia marina bark extract. The higher the concentration, the higher the average mortality rate of Aedes aegypti larvae.

Keywords: Avicennia marina, Aedes aegypti, Dengue Fever
\end{abstract}

\begin{abstract}
Abstrak: Efektifitas Biolarvasida Ekstrak Kulit Batang Avicennia Marina Terhadap Jentik Vektor Demam Berdarah (Aedes Aegypti). Data Kementrian Kesehatan Republik Indonesia, terhadap angka penderita Demam Berdarah Dengue (DBD) tahun 2013 tercatat 45,85 per 100.000 penduduk (112.511 kasus) dengan angka kematian sebesar $871(0,77 \%)$. Upaya pemerintah dan penggunaan obat nyamuk sintetis belum memberikan hasil yang optimal. Disamping itu, obat nyamuk sintetis mengandung senyawa kimia yang bersifat toksin bagi penggunanya. Penelitian ini bertujuan untuk mengetahui pengaruh toksisitas ekstrak kulit batang Avicennia marina terhadap kematian larva nyamuk Aedes aegypti. Penelitian ini menggunakan metode ekstraksi kulit batang Avicennia marina secara maserasi. Hasil ekstrak yang diperoleh diujikan toksisitasnya pada larva nyamuk Aedes aegypti dengan variasi konsentrasi 0 ppm, 1000 ppm, 2000 ppm, 3000 ppm, 4000 ppm dan 5000 ppm selama masa inkubasi 24 jam. Berdasarkan hasil pengamatan dan pembahasan, diketahui bahwa jumlah kematian larva setelah 24 jam perlakuan, pada konsentrasi terendah 1000 ppm sebesar 11 larva (55\%), konsentrasi 2000 ppm sebesar 18 larva ( $81 \%)$, konsentrasi 3000 ppm sebesar 20 larva (100\%), konsentrasi 4000 ppm sebesar 20 larva (100\%) dan konsentrasi 5000 ppm sebesar 20 larva $(100 \%)$. Peningkatan rata-rata kematian larva Aedes aegypti terjadi seiring dengan peningkatan konsentrasi ekstrak kulit batang Avicennia marina yaitu semakin tinggi konsentrasi maka semakin tinggi pula rata-rata kematian larva Aedes aegypti.
\end{abstract}

Kata kunci : Avicennia marina, Aedes aegypti, Demam Berdarah Dengue (DBD) 


\section{PENDAHULUAN}

Demam Berdarah Dengue (DBD) atau Dengue Haemorhagic Fever (DHF) merupakan penyakit dengan angka kejadian yang cenderung meningkat di daerah tropis dan sub tropis. $\mathrm{Di}$ Indonesia, jumlah kasus demam berdarah cenderung meningkat dari tahun ke tahun. Meningkatnya angka demam berdarah tersebut disebabkan oleh sulitnya pengendalian penyakit yang ditularkan oleh nyamuk Aedes aegypti. Indonesia merupakan salah satu negara endemik Demam Berdarah Dengue yang setiap tahun atau 5 tahun sekali selalu terjadi kejadian luar biasa di berbagai kota (Depkes - Departemen Kesehatan, Republic of Indonesia (2007); CDC and EH Yearly Report 2007; Jakarta).

Berdasarkan data Kementrian

Kesehatan Republik Indonesia, angka penderita Demam Berdarah Dengue (DBD) tahun 2013 tercatat 45,85 per 100.000 penduduk (112.511 kasus) dengan angka kematian sebesar $0,77 \%$ (871 kematian). Sedangkan pada tahun 2014 ini sampai awal bulan April tercatat angka penderita Demam Berdarah Dengue (DBD) sebesar 5,17 per 100.000 penduduk (13.031 kasus) dengan angka kematian sebesar 0,84\% (110 kematian). Berbagai upaya telah dilakukan oleh pemerintah untuk mengendalikan penyakit Demam Berdarah Dengue (DBD). Upaya-upaya tersebut meliputi: pemantauan jentik secara rutin dan berkala, Pemberantasan Sarang Nyamuk (PSN) melalui 3M (Menguras, Menutup, dan Mengubur), dan menabur larvasida, penyebaran ikan pada tempat penampungan air, serta pemakaian obat nyamuk seperti lotion dan obat nyamuk bakar yang dijual di pasaran.

Obat nyamuk yang digunakan masyarakat pada umumnya adalah obat nyamuk yang menggunakan bahan kimia sintesis seperti diethyltoluamide (DEET), diclorovinil dimethyl phosphat (DDP), malathion, parathion, dan lain-lain. Kandungan kimia tersebut memberikan efek samping pada kesehatan paru-paru manusia dan iritasi pada kulit. Penelitian menemukan kerusakan paru-paru yang diakibatkan dari satu obat nyamuk sama dengan kerusakan yang diakibatkan dari 100 batang rokok. Adanya kandungan dichlorovynil dimetyl phosfat (DDVP), zat yang berbahaya jika terus-terusan terpapar dalam jangka waktu panjang akan mengakibatkan kerusakan syaraf, pernapasan terganggu dan memicu kanker. Selain itu kandungan zat kimia yang terdapat di dalam obat nyamuk mampu membuat aktivitas enzim turun sehingga adanya pengaruh yang buruk terhadap hati dan reproduksi manusia (Revina, 2014).

Salah satu upaya untuk mengatasi masalah tersebut adalah dengan menggunakan bioinsektisida. Bioinsektisida ini berasal dari tumbuhan, sehingga memiliki tingkat keamanan yang tinggi karena tidak bersifat toksin bagi kesehatan manusia. Di samping itu, penggunaan bioinsektisida bersifat ramah lingkungan. Tumbuhan mangrove di Indonesia merupakan yang terbanyak di dunia, baik dari segi kuantitas area ( \pm $42.550 \mathrm{~km} 2$ ) maupun jumlah spesies ( \pm 45 spesies), serta memiliki ekosistem mangrove dan keragaman jenis tertinggi di dunia yang tersebar di wilayah pesisir Sumatra, Kalimantan, dan Papua (Spalding et al, 2001). Sampai saat ini masyarakat memanfaatkan mangrove untuk pakan ternak, sayuran, makanan, abu kayu untuk sabun cuci, serta menjadi lahan pekerjaan sehari-hari untuk petani mangrove dan nelayan. Belum banyak masyarakat yang mengetahui bahwa mangrove memiliki potensi sebagai obat-obatan (Wibowo dkk, 2009; Purwoko, 2005).

Avicennia marina merupakan salah satu jenis mangrove yang memiliki senyawa metabolit sekunder sebagai antiinsektisida. Senyawa-senyawa tersebut meliputi: saponin, alkaloid, tanin, flavonoid, triterpenoid, glikosida (Wibowo dkk, 2009). Penelitian tentang tumbuhan mangrove sebagai antinsektisida selama ini belum pernah diteliti sebelumnya, yang kemungkinan dapat digunakan untuk toksin nyamuk dan mengatasi peningkatan penyakit Demam Berdarah Dengue (DBD). Berdasarkan hal tersebut peneliti ingin mengetahui bagaimana toksisitas 
ekstrak kulit batang Avicennia marina terhadap kematian larva nyamuk Aedes aegypti dan konsentrasi ekstrak kulit batang Avicennia marina yang efektif terhadap kematian larva nyamuk Aedes aegypti.

\section{METODE}

Penelitian ini dilaksanakan pada tanggal 18 Agustus 2014 sampai dengan 20 September 2014 yang bertempat di Laboratorium Human Genetik Lembaga Penyakit Tropis Universitas Airlangga dan Laboratorium Biologi SMA Dr. Soetomo Surabaya.

\section{Persiapan Sampel}

Bahan yang digunakan dalam penelitian ini adalah kulit batang Avicennia marina, methanol absolute, aquadest dan larva nyamuk Aedes aegypti (instar 3) yang diperoleh dari Laboratorium Entomologi Lembaga Penyakit Tropis Universitas Airlangga Surabaya. Alat yang digunakan dalam penelitian yaitu Evaporator, blender, kertas saring, neraca digital, gelas kimia, gelas ukur, labu Erlemeyer, batang pengaduk, corong pisah, batang pengaduk, penyaring maserasi, hot plate stirer. Kulit batang mangrove Avicennia marina diperoleh dari daerah pembudidayaan mangrove Wonorejo, Surabaya. Kulit batang dicuci, dibersihkan dari debu, tanah atau bagian lain yang tidak diperlukan.

\section{Prosedur Pengekstrakan Kulit Batang Mangrove (Avicennia marina)}

Kulit batang dengan berat basah $\pm 5 \mathrm{~kg}$ diangin anginkan lalu di masukkan di dalam oven pengering dengan suhu $50^{\circ} \mathrm{C}$, kemudian digiling dengan alat penggiling. Setelah digiling semua diayak lalu ditimbang. Hasil ayakan dimaserasi dengan metanol dengan perbandingan 1 : 10 selama $3 \times 24$ jam, kemudian disaring. Tahap maserasi ini diulang beberapa kali sampai maserat yang diperoleh warnanya relatif jernih. Selanjutnya maserat yang diperoleh dipekatkan dengan alat penguap putar (rotary Evaporator), pada suhu $40-50^{\circ} \mathrm{C}$, sehingga diperoleh ekstrak metanol berbentuk pasta

\section{Uji Toksisitas biolarvasida}

Setiap ekstrak dilakukan pengujian terhadap larva nyamuk Aedes aegypti yang terdiri dari perlakuan dan kontrol. Setiap perlakuan, masing-masing digunakan 20 ekor larva nyamuk Aedes aegypti. Erlenmeyer sebanyak 6 buah disiapkan untuk pengujian, di mana 5 erlenmeyer digunakan untuk sampel dan 1 erlenmeyer untuk kontrol. Sampel dibuat dengan berbagai variasi konsentrasi yaitu: 5000 ppm, 4000 ppm, 3000 ppm, 2000 ppm dan 1000 ppm. Masing-masing larutan tersebut dimasukkan ke dalam erlenmeyer yang berbeda. Setelah itu dimasukkan 20 ekor larva nyamuk Aedes aegypti. Sebagai kontrol ke dalam erlemeyer dimasukkan larutan aquades ditambah dengan 20 ekor larva nyamuk Aedes aegypti. Pengamatan dilakukan 24 jam setelah perlakuan terhadap kematian larva.

\section{Analisis Data}

Pengumpulan data dilakukan dengan cara menghitung berapa persen jumlah kematian larva dalam kurun waktu 24 jam pada konsentrasi 5000 ppm, 4000 ppm, 3000 ppm, 2000 ppm dan 1000 ppm untuk mengetahui aktivitas ekstrak kulit batang mangrove Avicennia marina sebagai larvasida terhadap aedes aegypti melalui pengujian tersebut. 


\section{HASIL DAN PEMBAHASAN}

Hasil penelitian didapatkan sebagai berikut.

Tabel 1. Jumlah Kematian Larva Aedes aegypti pada Berbagai Konsentrasi Ekstrak Kulit Batang Avicennia marina setelah 24 Jam Perlakuan

\begin{tabular}{lccc}
\hline $\begin{array}{c}\text { Konsentrasi } \\
(\mathbf{p p m})\end{array}$ & Jumlah Larva uji & $\begin{array}{c}\text { Jumlah } \\
\text { Kematian Larva }\end{array}$ & $\begin{array}{c}\text { Presentasi } \\
\text { Kematian } \\
(\mathbf{\%})\end{array}$ \\
\hline 1. Sampel Kontrol & 20 & 0 & 0 \\
\hline 2. $1000 \mathrm{ppm}$ & 20 & 11 & $55 \%$ \\
\hline $3.2000 \mathrm{ppm}$ & 20 & 18 & $81 \%$ \\
\hline $4.3000 \mathrm{ppm}$ & 20 & 20 & $100 \%$ \\
\hline $5.4000 \mathrm{ppm}$ & 20 & 20 & $100 \%$ \\
\hline $6.5000 \mathrm{ppm}$ & 20 & 20 & $100 \%$ \\
\hline
\end{tabular}

Persentase kematian larva nyamuk Aedes aegypti pada berbagai konsentrasi

ekstrak kulit batang Avicennia marina dapat dilihat pada grafik berikut.

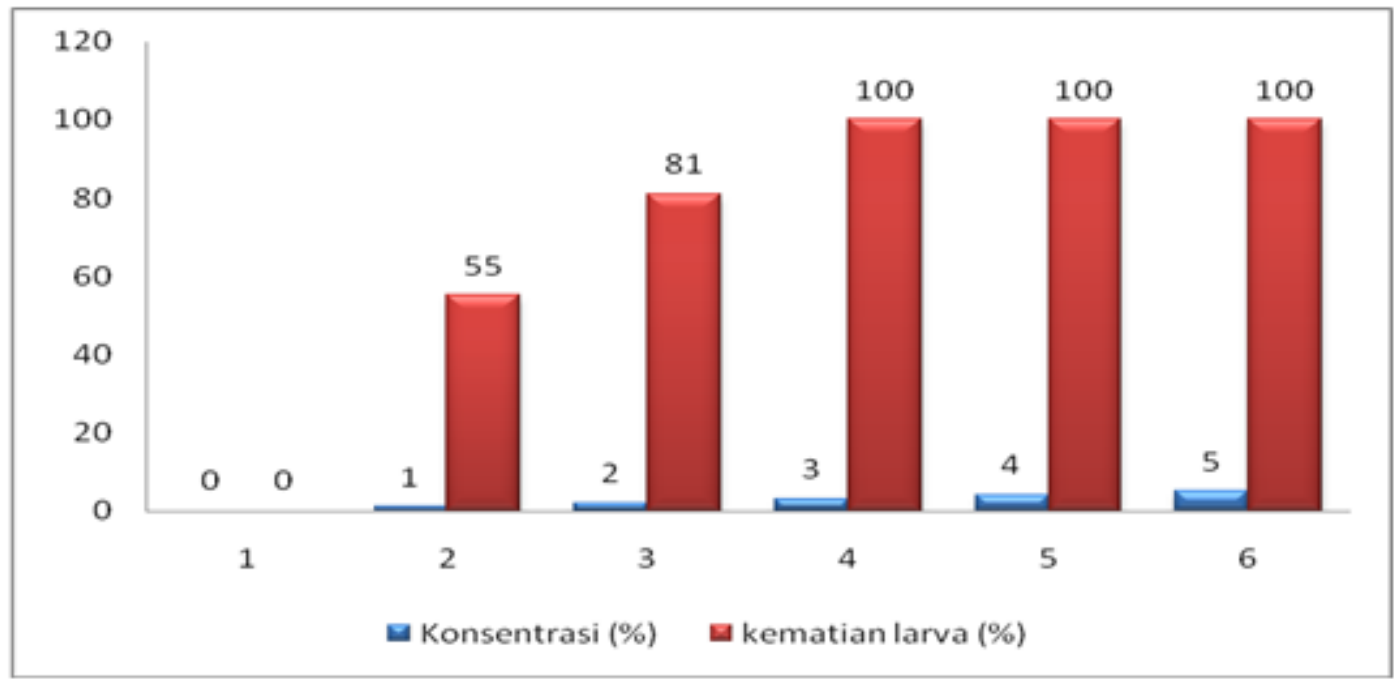

Gambar 1. Grafik Kematian Larva Nyamuk Aedes aegypti pada berbagai konsentrasi ekstrak kulit batang Avicennia marina.

Berdasarkan tabel 1 dapat diketahui bahwa pada kelompok kontrol tidak terdapat kematian larva uji. Jumlah kematian larva setelah 24 jam perlakuan, pada konsentrasi terendah 1000 ppm sebesar 11 larva (55\%), konsentrasi 2000 ppm sebesar 18 larva $(81 \%)$, konsentrasi 3000 ppm sebesar 20 larva (100\%), konsentrasi 4000 ppm sebesar 20 larva (100\%) dan konsentrasi 5000 ppm sebesar 20 larva (100\%). Peningkatan rata-rata kematian larva Aedes aegypti terjadi seiring dengan peningkatan konsentrasi ekstrak kulit batang Avicennia marina yaitu semakin tinggi konsentrasi maka semakin tinggi pula rata-rata kematian larva Aedes aegypti.

\section{PEMBAHASAN}

Insektisida alami (bioinsektisida) adalah suatu insektisida yang bahan dasarnya berasal dari alam, misalnya tumbuhan. Jenis insektisida ini mudah terurai di alam, misalnya tumbuhan. Jenis insektisida ini mudah terurai di alam sehingga tidak mencemarkan lingkungan dan relatif aman bagi 
manusia dan ternak, karena residunya akan terurai dan mudah hilang. Insektisida nabati dapat membunuh atau mengganggu serangan hama dan penyakit melalui cara kerja yang unik, yaitu dapat melalui perpaduan cara atau secara tunggal (Sugiata, 2011).

Kandungan senyawa kimia ekstrak kulit batang Avicennia marina terdiri dari alkaloida, saponin, flavonoida, tanin, dan triterpenoid (Wibowo,2009). Senyawa kimia tersebut diperoleh melalui proses ekstraksi dengan metode maserasi. Maserasi adalah proses pengekstrakan simplisia dengan menggunakan pelarut dengan beberapa kali pengocokkan atau pengadukan pada suhu kamar. Batang kulit ini, dimaserasi menggunakan pelarut methanol absolute (99\%) untuk memperoleh semua jenis senyawa kimia yang terkandung. Faktor-faktor yang menentukan hasil ekstraksi adalah waktu ekstraksi, perbandingan antar jumlah sampel dan pelarut, ukuran bahan dan suhu ekstraksi. Semakin lama waktu ekstraksi maka proses tumbukan antara bahan dan pelarut semakin besar. Sehingga dalam penelitian ini digunakan perbandingan antara hasil ayakan kulit batang dengan methanol yaitu 1 : 10 selama $3 \times 24$ jam.

Untuk mengetahui toksisitas dari ekstrak yang diperoleh, maka larva Aedes aegypti diberikan perlakukan ekstrak dengan 5 variasi konsentrasi termasuk kontrol. Hal ini bertujuan untuk mengetahui pengaruh konsentrasi ekstrak terhadap jumlah kematian larva selama masa inkubasi 24 jam. Dalam penelitian ini, peneliti menggunakan larva nyamuk instar 3 dengan ciri-ciri seluruh kulitnya menutupi bagian tubuh dan berubah jadi gelap dan keras. Sifon gemuk, warna lebih gelap dibandingkan dengan warna abdomen dan thorax. Larva berukuran 4-5 mm, duri-duri dada mulai jelas dan corong pernapasan berwarna coklat kehitaman (Wibowo, 2007). Di samping itu, toleransi terhadap toksin ekstrak kulit batang Avicennia marina sudah besar, jadi bisa dijadikan nilai tertinggi dibandingkan instar 1 dan 2.
Berdasarkan hasil pengamatan, diduga yang menyebabkan kematian larva di antaranya senyawa saponin. Senyawa ini komponen utamanya adalah sabun dan terdapat pada berbagai jenis tumbuhan dan bersamasama dengan substansi sekunder lainnya berperan sebagai pertahanan diri dari serangga-serangga. Saponin yang terdapat pada makanan yang dikonsumsi serangga, dapat menurunkan aktivitas enzim pencernaan dan penyerapan makanan (Ishaaya, 1986 dalam Prastiwi, 2007). Sementara, itu (Smith, 1989 dalam Prastiwi, 2007) menyatakan bahwa alkaloid, terpenoid dan flavanoid merupakan senyawa pertahanan tumbuhan yang dapat bersifat toksik.

Menurut Siswowijoto dalam Prastiwi (2007), gejala yang muncul bila hewan mengalami keracunan adalah melalui 4 fase yaitu perangsangan, kejang-kejang, kelumpuhan dan diakhiri tingkah laku hewan dari keadaan biasa, menjalar sampai tingkat antena dan bagian mulut. Gejala ini dilanjutkan pada tingkat kelumpuhan dan berlanjut pada organ respirasi akhirnya mengalami kematian.

\section{KESIMPULAN}

Berdasarkan hasil penelitian yang peneliti lakukan kulit batang Avicennia marina yang di ekstrak dengan metode maserasi dengan menggunakan pelarut methanol selama $3 \times 24$ jam dapat digunakan sebagai bioinsektisida. Ekstrak kulit batang Avicennia marina memiliki efek larvasida terhadap larva nyamuk Aedes aegypti dengan tingkat konsentrasi $50 \%$ pada konsentrasi larutan ekstrak 1000ppm dan tingkat konsentrasi $100 \%$ pada konsentrasi larutan ekstrak $3000 \mathrm{ppm}$. Semakin meningkat konsentrasi ekstrak kulit batang Avicennia marina didapatkan juga peningkatan jumlah kematian larva nyamuk Aedes aegypti sampai tingkat konsentrasi tertentu (5000 ppm).

\section{SARAN}

Penelitian ini dapat dikembangkan lebih lanjut sebagai repelen pada nyamuk dewasa. Perlu adanya 
penelitian lebih lanjut tentang berapa persen kandungan saponin dan flavonoid yang ada di kulit batang Avicennia marina.

\section{DAFTAR PUSTAKA}

Anggraini D.S. (2010). Stop Demam Berdarah Dengue, Bogor, Cita Insan Madani.

Anonim. (2012). Cara Penularan Penyakit Demam Berdarah Dengue. Diunduh dari http:/esejati.blogspot.com/2012/11/cara penularan penyakit demam berdarah dengue. Diakses $\mathrm{tgl} 28$ Agustus 2014.

Apriliasari. (2014). Makalah Nyamuk Aedes Aegypti. Diunduh dari http://apriliasari.blogspot.com/20 14/01/Makalah Nyamuk Aedes aegypti. Diakses tgl 25 Agustus 2014.

Depkes Republik Indonesia. (2007). Profil Kesehatan Indonesia 2006. Jakarta.

Hastuti, H. (2008). Daya Bunuh Ekstrak Daun Pandan Wangi (Pandanus amaryllifolius) Terhadap Larva Anophes aconitus donitz. Skripsi : Fakultas Kedokteran UNS : Surakarta

Prastiwi, Diah T. (2007). Indeks Pertumbuhan Larva Nyamuk Aedes aegypti Yang Terendah Dalam Ekstrak Kulit Jengkol (Pitheoellobatum lubatum benth) Unsoed.

Revina. (2014).Waspada bahaya Obat Nyamuk Bakar Bagi Kesehatan.
Diunduh dari http://bidanku.com, diakses tgl 25 Agustus 2014

Robertson, AJ., Alongi, D.M(eds). (1992). Tropical Mangrove Ecosystem Coastal and Estuarine Studies 41 American Geophysical Union, Washington, DC. P 329.

Saraswati. (2004). Pengaruh Konsentrasi Filtrat Biji Bengkuang (Pachyrrhizus erosus L) Terhadap Mortalitas Larva Nyamuk Aedes aegypti L. Skripsi. UMM. Malang.

Setyawan AD, Susilowati A, Sutarno. (2002). Biodiversitas Genetik, Spesies, dan Ekosistem Mangrove Di Jawa. H: 107.

Soegijanto, Soegeng. (2006). Demam Berdarah Dengue, Edisi Kedua. Surabaya: Airlangga University Prees. Hal 240 - 256.

Wibowo C, Kusmana C, Suryani A, Hartati Y, Oktadiyani P. (2009). Pemanfaatan Pohon Mangrove Api-api (Avicennia spp) Sebagai Bahan Pangan Dan Obat. Diunduh dari

http://repository.ipb.ac.id/bitstre m/handle/123456789/45052/Pem anfaatan\%20Pohon\%20Mangrove .pdf?sequense $=1$. Diakses

Wijayanti ED. (2007). Pengaruh Pemberian Ekstrak Daun Api-api (Avicennia marina) Terhadap Resorpsi Embrio, Berat Badan dan Panjang Badan Janin Mencit (Mus musculus). Skripsi, Fakultas Kedokteran Hewan Universitas Airlangga. 